\title{
Apoptosis and growth arrest induced by platinum compounds in U2-OS cells reflect a specific DNA damage recognition associated with a different p53-mediated response
}

\author{
L Gatti ${ }^{1}$, R Supino ${ }^{1}$, P Perego ${ }^{1}$, R Pavesi ${ }^{1}$, C Caserini ${ }^{1}$, \\ N Carenini ${ }^{1}$, SC Righetti ${ }^{1}$, V Zuco ${ }^{1}$ and F Zunino*,1 \\ 1 Istituto Nazionale per lo Studio e la Cura dei Tumori, 20133 Milan, Italy \\ * Corresponding author: Franco Zunino, Istituto Nazionale Tumori, Via \\ Venezian 1, 20133 Milan, Italy. Tel: +39-02-23902267; Fax +39-02-23902692; \\ E-mail: zunino@istitutotumori.mi.it
}

Received 27.3.02; revised 28.6.02; accepted 23.7.02 Edited by V De Laurenzi

\begin{abstract}
Mononuclear and multinuclear platinum complexes are known to induce distinct types of DNA lesions and exhibit different profiles of antitumor activity, in relation to p53 mutational status. In this study, we investigated the cellular effects of exposure to two platinum compounds (cisplatin and the multinuclear platinum complex BBR 3464), in the osteosarcoma cell line, U2-OS, carrying the wild-type p53 gene and capable of undergoing apoptosis or cell cycle arrest in response to diverse genotoxic stresses. In spite of the ability of both compounds to up-regulate p53 at cytotoxic concentrations, exposure to BBR 3464 resulted in cell cycle arrest but only cisplatin was capable of inducing significant levels of apoptosis and phosphorylation at the Ser15 residue of p53. The cisplatin-induced protein phosphorylation, not detectable in cells treated with BBR 3464, was associated with RPA phosphorylation, a specific up-regulation of $B a x$ and downregulation of $\mathrm{p} 21^{\mathrm{WAF} 1}$. Cells treated with BBR 3464 displayed a different cellular response with evidence of cytostasis associated with a high induction of p21 WAF1 . The regulation of p21 ${ }^{\text {WAF1 }}$ after cisplatin or BBR 3464 exposure required a p53 signal, as documented using stable transfectants expressing a dominant-negative form of p53 $\left(175^{\text {his }}\right)$. Taken together, these results indicate that cellular response to different genotoxic lesions (i.e. apoptosis or growth arrest) is associated with a specific recognition of DNA damage and a different p53-mediated signaling pathway. Multinuclear platinum complexes could be regarded as useful tools for investigating the p53-mediated process of cell cycle arrest in response to DNA damage.

Cell Death and Differentiation (2002) 9, 1352 - 1359. doi:10.1038/ sj.cdd. 4401109
\end{abstract}

Keywords: platinum complex; apoptosis; cell cycle arrest; p53 phosphorylation
Abbreviations: $\mathrm{IC}_{50}$ and $\mathrm{IC}_{80}$, drug concentrations inhibiting cell proliferation by $50 \%$ and $80 \%$; PI, propidium iodide; TUNEL, Idtmediated $\underline{\text { dUTP }}$ nick-end labeling

\section{Introduction}

The multinuclear platinum compound BBR 3464 exhibits unique DNA binding characteristics ${ }^{1}$ and the profile of DNA adduct formation by BBR 3464 is distinctly different from that of cisplatin. ${ }^{2}$ Surprisingly, the multinuclear platinum complex BBR 3464 is more effective than cisplatin in tumor cells lacking a functional p53, thus suggesting a different role of p53 in cellular response to peculiar drug-induced DNA lesions. In particular, the introduction of a wild-type p53 gene in a p53-null tumor cell line (SAOS) increases the sensitivity to cisplatin, but reduces the cytotoxic effects of BBR $3464 .^{3}$ The tumor suppressor gene p53 is a multifunctional transcriptional regulator, which plays a critical role in coordinating cellular response to DNA damage. ${ }^{4,5}$ The best known functions of $\mathrm{p} 53$ are regulation of cell cycle progression and induction of apoptosis. ${ }^{6,7}$ P53 itself has been implicated in detection of the DNA damage either alone or in cooperation with other factors. ${ }^{8,9}$ Modulation of p53 activity in response to DNA damage involves post-translational modifications including phosphorylation. ${ }^{10,11}$ In particular, phosphorylation at Ser15 is induced by genotoxic stresses including UV and ionizing radiation. ${ }^{12-14}$ The final outcome of p53 activation and the cellular fate following DNA damage appear to depend on a variety of cell type-specific factors that modulate the signaling pathways. However, the molecular mechanism underlying the control of a cellular decision between cell cycle arrest and apoptosis in response to genotoxic stress is still unknown.

The present study was undertaken with the aim to better understand the role of p53 in response to different types of DNA damage induced by platinum compounds. The study was performed in a human osteosarcoma cell line (U2-OS) carrying a wild-type p53 gene and known to undergo p53-dependent apoptosis or growth arrest induced by different types of radiation. ${ }^{15}$ The results indicated that, in contrast to cisplatin which induced an apoptotic response, the treatment with the multinuclear complex resulted in cell cycle arrest and cytostasis. Cisplatin-induced apoptosis was associated with a marked induction of p53 expression and phosphorylation of Ser15. The treatment with cisplatin and BBR 3464 resulted in a different regulation of downstream effectors (Bax, $\left.\mathrm{p} 21^{\mathrm{WAF} 1}\right)$. These results are consistent with a specific recognition of different types of DNA lesions, resulting in different p53-dependent responses, and contribute to 
clarify the molecular mechanism regulating the cellular switch between apoptosis and growth arrest in response to DNA damage.

\section{Results}

\section{Cellular outcome following exposure to platinum- containing agents: cytotoxicity and cytostasis}

In a human osteosarcoma cell line (U2-OS), BBR 3464 was about 20 times more potent than cisplatin in inhibiting cell growth; the $\mathrm{IC}_{50}$ values, determined $72 \mathrm{~h}$ after $1 \mathrm{~h}$ drug exposure, were $0.8 \pm 0.2$ and $13 \pm 2.5 \mu \mathrm{M}$ for BBR 3464 and cisplatin, respectively (Figure $1 \mathrm{~A}$ ).

The drug effect was also examined by colony forming assay. In this assay, drug exposure was performed on small size colonies (4-8 cells) exposed to the drug and then counted after about three cell cycles when untreated colonies consisted of more than 30 cells. Figure 1B shows

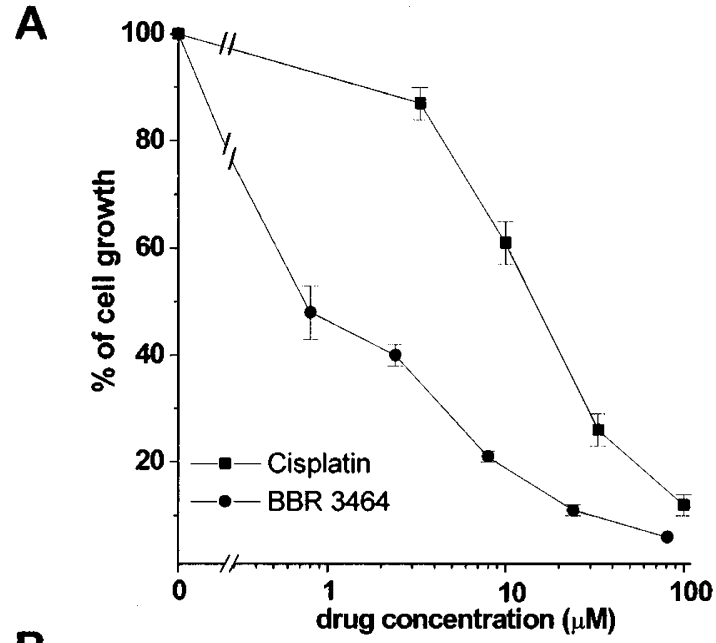

B

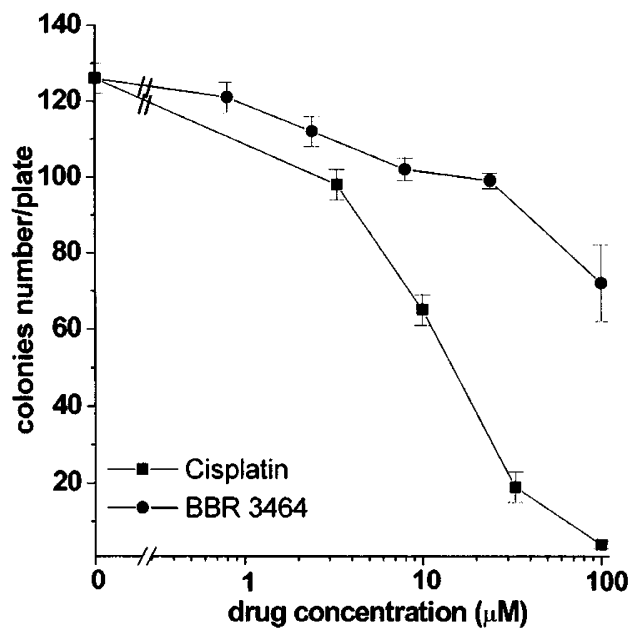

Figure 1 Antiproliferative effects of cisplatin or BBR 3464 on U2-OS cell line. (A): Drug effect after $1 \mathrm{~h}$ exposure was determined by cell counting $72 \mathrm{~h}$ after treatment; (B): colony growth inhibition; treatment was performed 5 days after cell seeding. Mean \pm S.D. of at least three independent experiments the dose-response curves in terms of residual colony number. The number of colonies treated with cisplatin was substantially reduced at concentrations higher than $3 \mu \mathrm{M}$. The inhibition of colony number was dose-dependent with an almost complete disappearance after exposure to $100 \mu \mathrm{M}$ cisplatin. In contrast, only a marginal effect of BBR 3464 was found up to $30 \mu \mathrm{M}$ and a significant number of colonies was still observed after exposure to $100 \mu \mathrm{M}$ BBR 3464. These results are consistent with a cytotoxic effect of cisplatin and a cytostatic effect of BBR 3464.

\section{Relationships between antiproliferative effects and apoptotic cell death induced by platinum compounds}

To determine whether drug exposure resulted in apoptotic cell death, we performed (a) fluorescence microscopy analyses of apoptosis-associated nuclear changes in $\mathrm{PI}$ stained cells, and (b) cytofluorimetric analysis of fragmented DNA of apoptotic cells by TUNEL assay. With both analyses, the percentage of apoptotic cells found at $72 \mathrm{~h}$ after drug exposure was higher with cisplatin than with the multinuclear platinum compound. Although specific markers of apoptosis could be detected at earlier times, in this study apoptosis was determined at $72 \mathrm{~h}$, because at this time the maximum extent of apoptosis was found. With drug concentrations generating similar levels of $\mathrm{Pt}-\mathrm{DNA}$ adducts $(50 \mu \mathrm{M}$ for cisplatin and $16 \mu \mathrm{M}$ for BBR 3464), BBR 3464 induced lower levels of apoptosis than cisplatin (Figure 2A,B). No early (Figure $2 \mathrm{~A}$ ) or delayed manifestations of apoptosis were found up to $144 \mathrm{~h}$ in BBR 3464-treated cells. Inhibition of cell growth induced by the multinuclear platinum compound was associated with a negligible extent of necrosis, as evaluated by annexin $\mathrm{V}$ binding assay (Figure $2 \mathrm{~A}$ ). U2-OS cells treated with BBR 3464 appeared strictly adherent to the flask. Indeed, Figure 3 shows the relationship between the extent of drug-induced apoptosis and cell growth inhibition in the range of drug concentrations $(50-100 \mu \mathrm{M}$ and $16-50 \mu \mathrm{M}$ for cisplatin and BBR 3464, respectively) causing a comparable marked antiproliferative effect. Under these conditions, which favour a prompt apoptotic response by cisplatin treatment, BBR 3464 exhibited a substantially reduced ability to induce apoptosis.

\section{Cell cycle perturbations following DNA damage}

An analysis of cell cycle perturbations was performed on cells exposed to cisplatin or BBR 3464 at different times after $1 \mathrm{~h}$ drug-exposure (Figure 4). Drug concentrations inducing a similar antiproliferative effect and a comparable extent of DNA platination ${ }^{2}$ (50 $\mu \mathrm{M}$ for cisplatin and $16 \mu \mathrm{M}$ for BBR 3464) induced differential cell cycle perturbations. A marked and persistent increase in S-phase was observed at $24 \mathrm{~h}$ after treatment with $50 \mu \mathrm{M}$ cisplatin. At the tested concentration, BBR 3464 caused a persistent accumulation of cells in G2/M-phase without disappearance of cells in G1-phase up to $72 \mathrm{~h}$. Thus, the antiproliferative activity of BBR 3464 can be at least in part related to a persistent block in G1- and G2phases. 


\section{p53 phosphorylation at Ser15 is induced by cisplatin but not by the multinuclear platinum complex}

To examine the role of p53 in the response of U2-OS cells to DNA damage, p53 expression was examined at 6 and $24 \mathrm{~h}$ after a $1 \mathrm{~h}$ exposure to drug concentrations generating similar levels of Pt-DNA adducts ${ }^{2}$ (Figure 5). Both agents caused an increase in p53 protein level which was more marked following cisplatin treatment. Cisplatin, but not BBR 3464, determined p53 protein phosphorylation at Ser15 as documented by using a phospho-p53 Ser15 antibody. The phosphorylated protein could be detected
$6 \mathrm{~h}$ following treatment (Figure 5A), but phosphorylation was more marked at $24 \mathrm{~h}$ (Figure 5B). Exposure to $\gamma$-rays resulted in p53 phosphorylation at early time points (i.e. $1 \mathrm{~h}$, not shown). Twenty-four hours after $1 \mathrm{~h}$ exposure (Figure 5B), BBR 3464 induced up-regulation of p21 WAF1, whereas cisplatin exposure resulted in $\mathrm{p} 21^{\mathrm{WAF} 1}$ downregulation. Similar effects were observed when cells were exposed to equimolar concentrations of cisplatin and BBR 3464 (Figure 6A). Moreover, exposure to $50 \mu \mathrm{M}$ cisplatin but not BBR 3464, resulted in phosphorylation of the 32$\mathrm{kDa}$ subunit of RPA (Figure 6B). When using drug concentrations capable of inducing similar amounts of p53 protein in U2-OS cells, Ser15 phosphorylation was
A
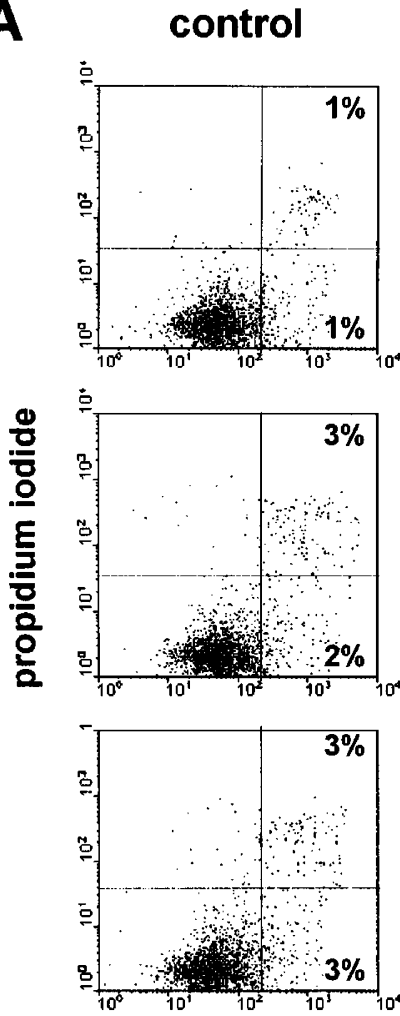

B

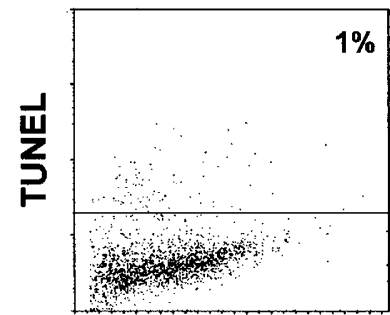

cisplatin
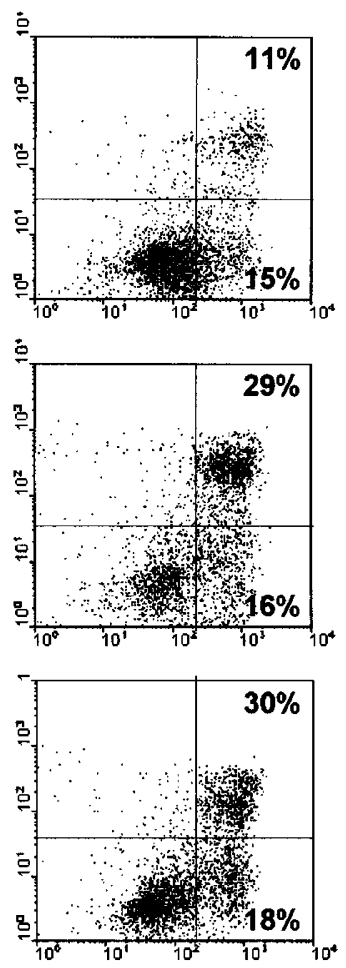

annexin $\mathbf{V}$

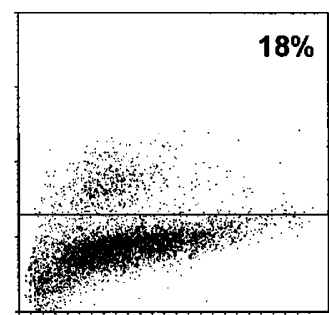

FSC
BBR 3464

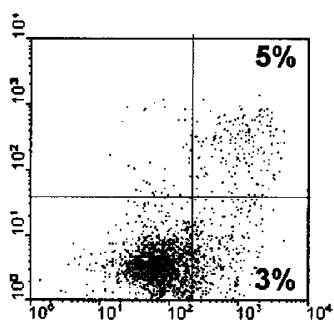

24h

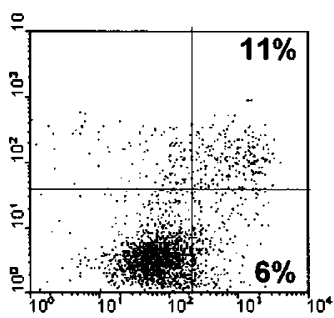

$48 h$

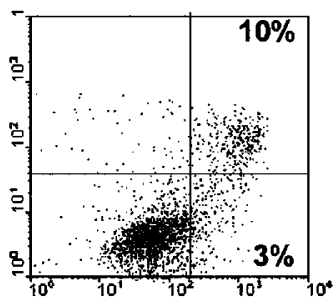

$72 h$

Figure 2 Induction of apoptosis after treatment with cisplatin or BBR 3464. Treatment was with concentrations generating similar levels of Pt-DNA adducts $(50 \mu \mathrm{M}$ for cisplatin and $16 \mu \mathrm{M}$ for BBR 3464). Apoptosis was measured by flow cytometric analysis of (A) annexin V binding at different time points and (B) Tdtmediated dUTP biotin nick-end labeling (TUNEL) assay at $72 \mathrm{~h}$ after treatment. In (A) early apoptotic cells are in the low right quadrant (Annexin V-positive, propidium iodide-negative), whereas necrotic and late apoptotic cells are in the up-right quadrant (Annexin V-and propidium iodide-positive). FSC, forward scatter 
detectable only in cisplatin-treated cells (data not shown). To elucidate whether regulation of $\mathrm{p} 21^{\mathrm{WAF} 1}$ requires a $\mathrm{p} 53$ signal at all, we prepared stable transfectants (U2-OS/175 cells) expressing a dominant-negative form of p53 (p53$\left.175^{\text {his }}\right)$. Transfection resulted in an almost complete suppression of p21 WAF1 expression in U2-OS/175 cells as compared to the empty vector transfected cells U2-OS/e (Figure 7) and untransfected U2-OS cells (not shown). Exposure to either cisplatin or BBR 3464 did not evidence expression of p21WAF1. Only overexposure of the film allowed detection of residual p21 WAF1 expression in U2OS/175 cells. Under these extreme conditions (Figure 7), lack of BBR 3464-induced up-regulation was found, and also cisplatin-induced p21 WAF1 down-regulation was marginally appreciable. Likely as a consequence of loss of p21 WAF1 function, U2-OS/175 cells exhibited a reduced ability to arrest in G1 phase under the impact of BBR 3464 (Figure 8). No significant differences in cell cycle perturbations were observed between the U2-OS and U2-OS/e cells.

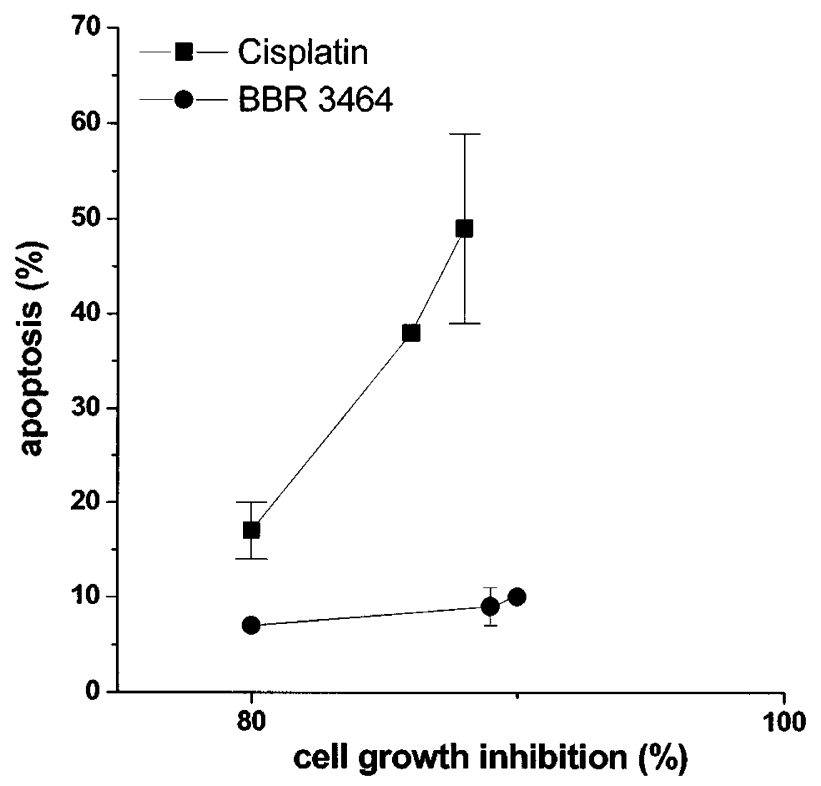

Figure 3 Relationship between cell growth inhibition and apoptosis level in U2-OS cells. Cells were treated for $1 \mathrm{~h}$ and antiproliferative effect and apoptosis levels were determined $72 \mathrm{~h}$ later. Values are the mean + S.D. of at least three independent experiments
Induction of p53 phosphorylation by cisplatin was associated with a delayed increase of expression of the proapoptotic protein Bax (48 h after treatment; Figure 9). Again, the effect of BBR 3464 was marginal.

In an attempt to support the general relevance of the effects described in the U2-OS osteosarcoma model system, we examined p53 phosphorylation at Ser 15 in other cell systems of different tumor types (e.g. ovarian carcinoma). When the IGROV-1 and A2780 cell lines were exposed to drug concentrations producing similar growth inhibition $\left(\mathrm{IC}_{80}\right)$, we observed induction of p53 phosphorylation by cisplatin but not by BBR 3464 (Figure 10).

\section{Discussion}

The peculiar behaviour of U2-OS cells with wild-type p53 in response to platinum compounds has provided the

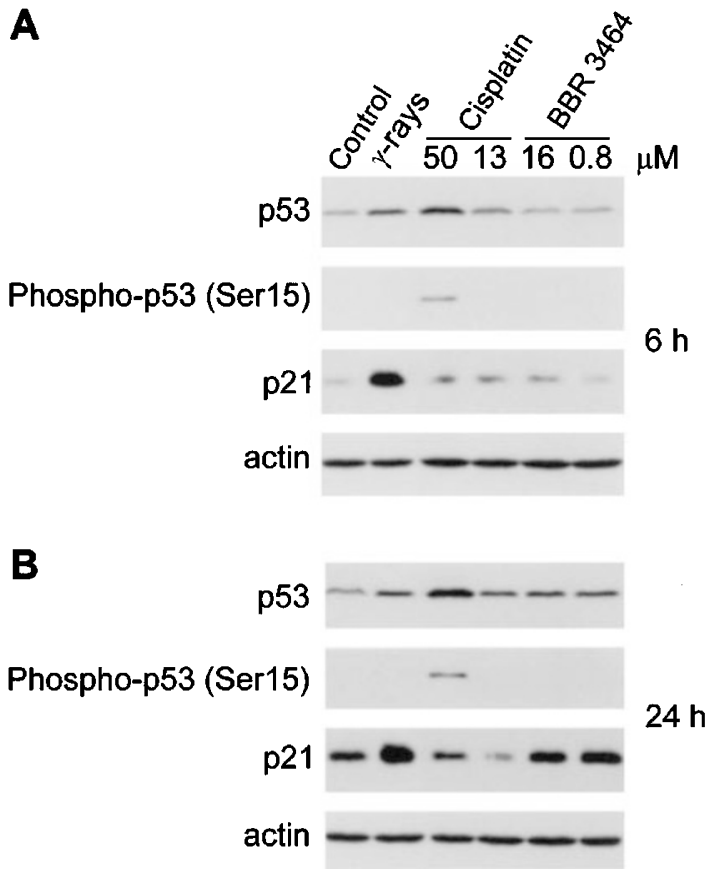

Figure 5 Western blot analysis of p53, phospho-p53 (Ser15) and p21 protein levels in U2-OS cells. Cells were exposed to drug concentrations generating similar levels of Pt-DNA adducts for $1 \mathrm{~h}$ or to $\gamma$-rays, and harvested $6(\mathbf{A})$ and $24 \mathrm{~h}$ (B) after treatment. Control loading is shown by actin
Control

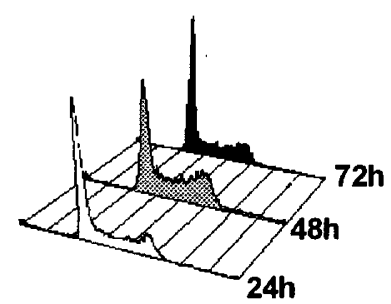

Cisplatin $50 \mu \mathrm{M}$

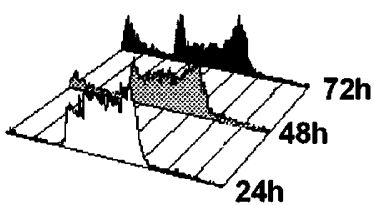

BBR $346416 \mu \mathrm{M}$

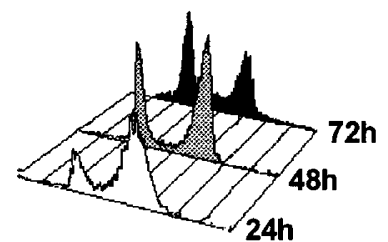

Figure 4 Time course of U2-OS cell cycle distribution after exposure to cisplatin or BBR 3464. Cells were harvested at different times and then fixed, stained with propidium iodide and analyzed by flow cytometry. One experiment representative of three is reported 
opportunity for investigating p53-mediated response according to the type of DNA lesions. Multinuclear platinum complexes, containing two reactive platinum centers linked by a relatively long chain, were originally designed to form 'Iong-distance' DNA cross-links. ${ }^{1,16}$ Indeed, the multinuclear complex BBR 3464 is able to form DNA lesions different

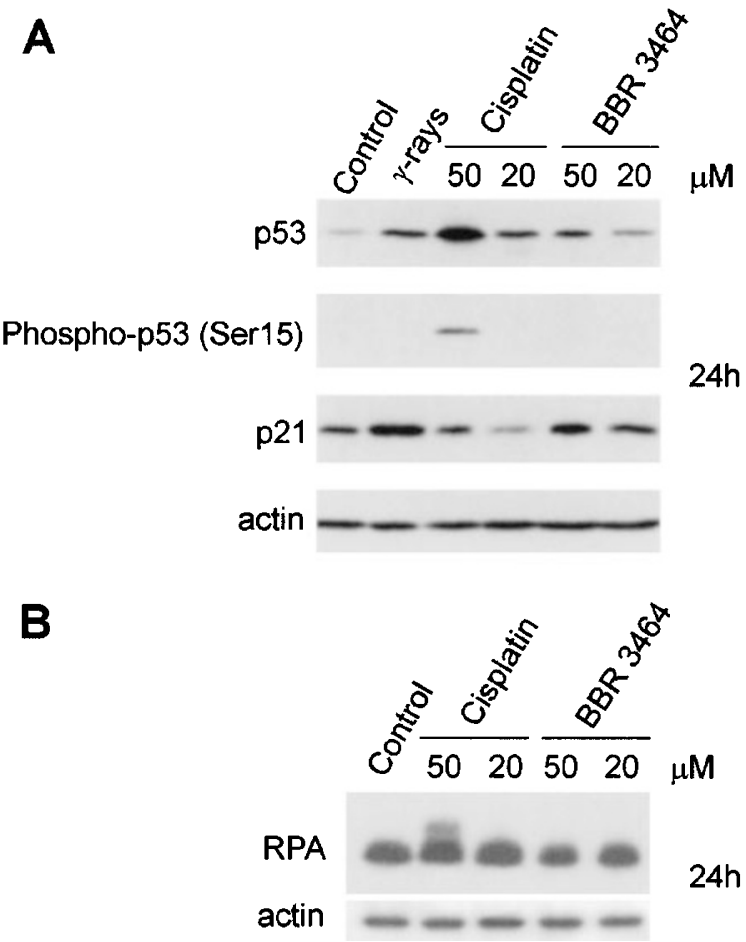

Figure 6 Western blot analysis of p53, phospho-p53 (Ser15), p21 WAF1 (A) and RPA (B) protein levels in U2-OS cells. Cells were exposed to equimolar drug concentrations for $1 \mathrm{~h}$ or to $\gamma$-rays, and harvested $24 \mathrm{~h}$ after treatment. Control loading is shown by actin from those induced by cisplatin and to elicit a cellular response different from that of cisplatin. ${ }^{2}$ The results of our study clearly document that BBR 3464 exhibited unusual features that could underlie the completely different pattern of cellular response compared to cisplatin. In spite of its marked antiproliferative potential and ability to bind to DNA ${ }^{2}$ the multinuclear platinum complex appeared unable to trigger marked apoptosis in a cell model which retains a wild-type p53 and an efficient apoptotic machinery, as documented by the apoptotic response to cisplatin (Figure 2). Indeed, the antiproliferative effects of BBR 3464 against U2-OS cells could be ascribed to a persistent arrest in G1 and G2 phases (Figure 4). Such a cellular response is consistent with wild-type p53 function at these specific checkpoints. Relevant to this point is the up-regulation of p21 ${ }^{\text {WAF } 1}$ by BBR 3464 in contrast to down-regulation by cisplatin. The role of $\mathrm{p} 21^{\mathrm{WAF} 1}$ regulation by wild-type $\mathrm{p53}$ is clearly documented by introduction of a mutant p53 with a

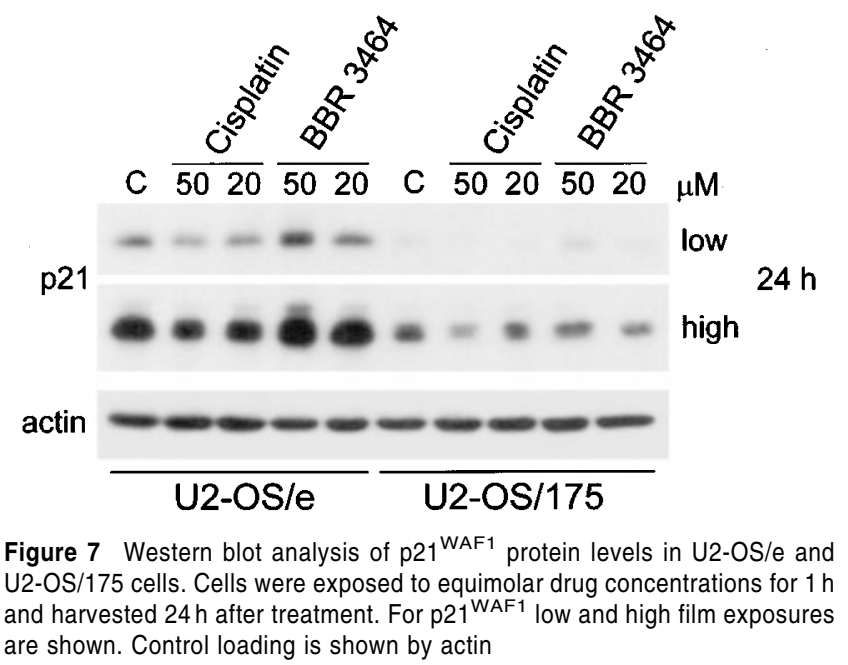

Control
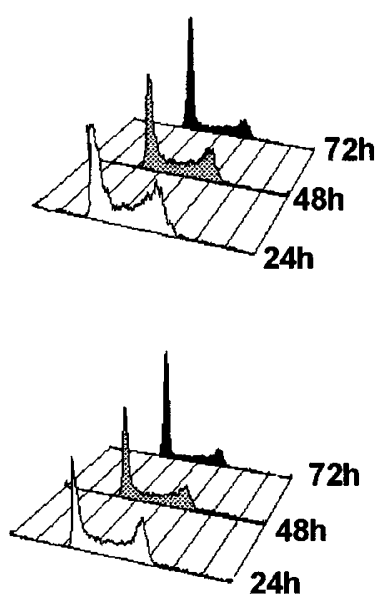

Cisplatin $50 \mu \mathrm{M}$
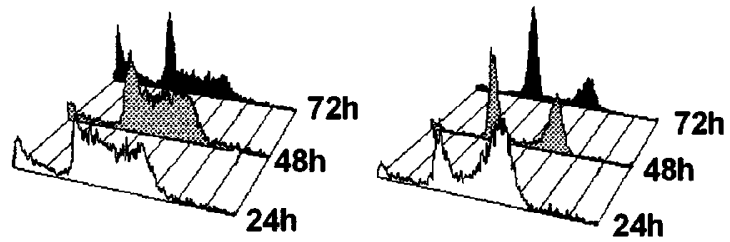

U2OS/175
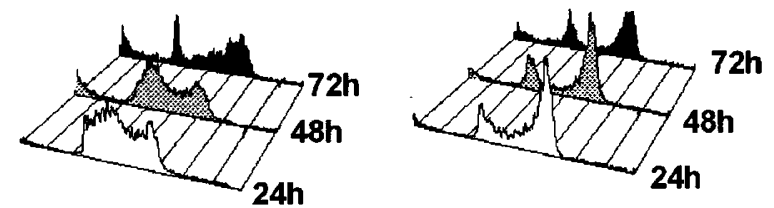

Figure 8 Cell cycle distribution of U2-OS/e and U2-OS/175 cells. At different times after drug exposure to cisplatin or BBR 3464, cells were fixed, stained with propidium iodide and analyzed by flow cytometry. A representative experiment is shown 


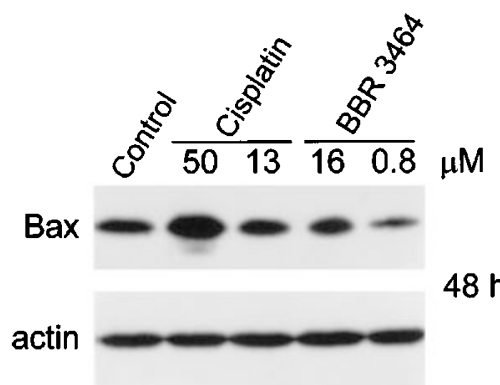

Figure 9 Western blot analysis of Bax protein levels in U2-OS cells. Cells were exposed for $1 \mathrm{~h}$ to drug concentrations generating similar levels of PtDNA adducts, and harvested $48 \mathrm{~h}$ after treatment. Control loading is shown by actin

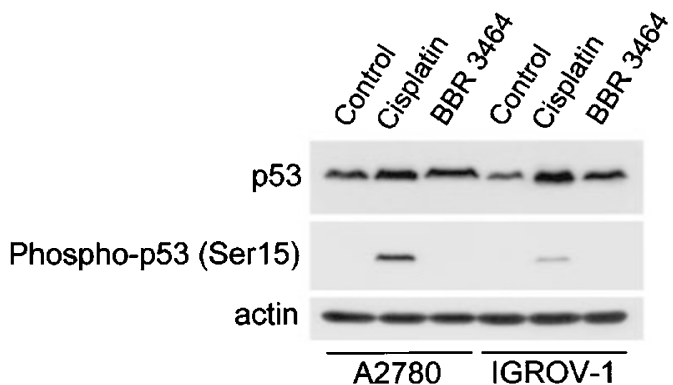

Figure 10 Western blot analysis of p53 and phospho-p53 (Ser15) protein levels in A2780 and IGROV-1 ovarian carcinoma cell lines. Cells were exposed for $1 \mathrm{~h}$ to drug concentrations producing similar growth inhibition $(10 \mu \mathrm{M}$ cisplatin and $0.08 \mu \mathrm{M}$ BBR 3464 for A2780 cells; $30 \mu \mathrm{M}$ cisplatin and $8 \mu \mathrm{M}$ BBR 3464 for IGROV-1 cells) and harvested $24 \mathrm{~h}$ after treatment. Control loading is shown by actin

dominant negative effect, resulting in a reduced ability of BBR 3464-treated cells to arrest in G1 and in lack of p21 WAF1 up-regulation. In contrast, cisplatin caused a down-regulation of p21 WAF1 which could favour the decision toward the apoptotic response.

The most relevant finding of this study was a close association between cisplatin-induced apoptosis, Ser15 phosphorylation of the p53 protein and RPA phosphorylation (Figures 5 and 6 ). This kind of response found in U2-OS cells appears to be a general phenomenon, as Ser15 phosphorylation was induced by cisplatin but not by BBR 3464 in other cell systems (Figure 10). In contrast to cisplatin, BBR 3464 was unable to induce p53 or RPA phosphorylation and apoptosis in U2-OS cells under the same conditions, i.e. at concentrations causing a comparable antiproliferative effect. Relevant to this point is the observation that cisplatin-induced p53 phosphorylation could be detected at concentrations $(50 \mu \mathrm{M})$ which caused a substantial apoptotic response. The precise role of p53 phosphorylation in regulating its function is still controversial. Previous studies have provided opposite interpretations about the physiological role of phosphorylation on transcriptional transactivation function. ${ }^{10,17}$ Activation of p53 transcriptional activity requires phosphorylation of multiple $\mathrm{N}$-terminal serine residues, including Ser15. ${ }^{18,19}$ Ser15 phosphorylation could result in the accumulation of p53 via inhibition of MDM2 interaction and protein degradation. ${ }^{12,20}$ Both Ser15 and 20 appear to be important at least in the regulation of p53-mediated apoptosis. ${ }^{21}$ Analysis of individual mutants revealed that mutations in these specific residues of p53 are primarily responsible for impairment of its apoptotic activity. ${ }^{21}$ The relevance of phosphorylation of Ser15 for apoptosis has been emphasized by the observation that apoptosis induced by p53 gene transfer was partially inhibited by a p53 mutant at Ser15 in glioma cells. ${ }^{22}$

Distinct pathways for growth arrest and apoptosis appear to be related to a selective induction of gene products specific for each pathway. Indeed, cisplatininduced phosphorylation of p53 was accompanied by induction of Bax (Figure 9), a well known pro-apoptotic factor. $^{23}$ This induction was clearly evident at a concentration causing substantial levels of apoptosis (Figure 2). In contrast, cellular response to BBR 3464 was characterized by increased expression of p21 WAF1 (Figures 5 and 6), which is a major effector of p53mediated growth arrest following DNA damage. ${ }^{24} \mathrm{~A}$ similar pattern of up-regulation of Bax by cisplatin and p21 WAF1 by BBR 3464 has been observed in astrocytoma cells. ${ }^{25}$

The different cellular responses of drug-treated U2-OS cells are reminiscent of those observed in the same cell line following genotoxic damage induced by different forms of radiation. ${ }^{15}$ The latter study does not provide an explanation of the dual function of $\mathrm{p} 53$ in response to different types of genotoxic stress. On the basis of the findings of our study, it is tempting to speculate that the initiation of apoptosis is related to a differential recognition of specific DNA lesions resulting in different signaling processes. This interpretation, which implies the existence of multiple sensors mediating distinct cellular signals in response to different DNA lesions, is consistent with RPA and p53 phosphorylation (Figures 5 and 6). RPA is implicated in recognition of Pt-DNA adducts and in signaling of DNA lesions. ${ }^{26,27}$ The interaction between p53 and RPA is disrupted when RPA is phosphorylated following DNA damage, and the release of p53 allows the activation of downstream genes. ${ }^{28}$ Phosphorylation of both RPA and p53 at Ser15 is performed by DNA-PK or ATM. ${ }^{27,29}$ Our study does not rule out the possibility that other posttranslational modifications are involved in cellular response to different cytotoxic stresses, but it only emphasizes that diverse types of DNA lesions elicit a different p53-mediated cellular response, likely resulting in a different cellular outcome.

Finally, since the presence of a functional p53 is expected to induce a cytostatic rather than cytotoxic effect in response to the multinuclear platinum compound, a differential p53-dependent response to mononuclear or multinuclear platinum compounds could account for a reduced efficacy of BBR 3464 against preclinical models of human tumors with wild-type $p 53^{30}$ 


\section{Materials and Methods}

\section{Drugs and chemicals}

Cisplatin (Platinex) was purchased from Bristol Myers Squibb (Rome, Italy); BBR 3464 was synthesized and provided by NovusPharma S.p.A. (Monza, Italy). Both drugs were dissolved in $0.9 \% \mathrm{NaCl}$ before use.

\section{Cell culture conditions and treatments}

The U2-OS osteosarcoma cell line (ATCC, HTB 96) was maintained in McCoy's 5A medium (Bio-Whittaker, Verviers, Belgium) supplemented with $10 \%$ fetal calf serum (Life Technologies, Gaithersburg, MD, USA). The A2780 and IGROV-1 ovarian carcinoma cell lines were maintained in RPMI-1640 medium (Bio-Whittaker) supplemented with $10 \%$ fetal calf serum (Life Technologies).

In all experiments, $24 \mathrm{~h}$ after seeding, cells were treated with different concentrations of cisplatin or BBR 3464 for $1 \mathrm{~h}$ and then incubated in drug-free medium for different times.

\section{Transfection procedures}

Stable transfectants of U2-OS cells were prepared by lipofection. Cells were seeded in $5 \mathrm{~cm}^{2}$ diameter dishes and when they reached $70 \%$ confluency they were incubated with serum free medium containing $20 \mu \mathrm{l}$ of lipofectin and $3 \mu \mathrm{g}$ of plasmid DNA for $5 \mathrm{~h}$. DNA consisted of a plasmid expressing a dominant-negative form of p53 mutagenized at

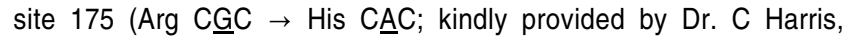
National Cancer Institute, Bethesda, MD, USA) or an empty vector for negative control. Stable transfectants were selected in the presence of G418 $(400 \mu \mathrm{g} / \mathrm{ml})$.

\section{Cell sensitivity studies}

Cell sensitivity to drugs was measured by growth inhibition and colony forming assays. In the former assay, adherent cells were trypsinized and counted at different times after drug treatment by a coulter counter (Coulter Electronics, Luton, UK). Cell growth inhibition was determined as per cent of treated cells relative to control cells. The results are the mean of at least three independent experiments. In the colony forming assay, 500 cells were seeded in $60 \mathrm{~mm}$ plates (Corning Costar, Corning, NY, USA) in triplicate and, when colonies were detectable ( 5 days after seeding), cells were treated with the drugs for $1 \mathrm{~h}$. They were incubated in drug-free medium until colonies in control samples consisted of around 30 cells. Samples were stained with $1 \%$ crystal violet in methanol for $30 \mathrm{~min}$, and then colonies formed of at least eight cells were counted by an inverse microscope.

\section{Assessment of apoptosis and necrosis}

Apoptosis and necrosis were detected by microscopic analysis of $\mathrm{PI}$ stained cells by TUNEL assay and by annexin V binding assay.

Floating and trypsinized cells were washed in phosphate-buffered saline (PBS), counted, fixed in $70 \%$ ice-cold ethanol and stained with a PI solution (30 $\mu \mathrm{g} / \mathrm{ml} \mathrm{PI,} 66 \mathrm{U} / \mathrm{ml}$ RNAse A in PBS) for $30 \mathrm{~min}$. Cells were examined and counted for nuclear morphology by a fluorescence microscope.

In the TUNEL assay, cells $\left(5 \times 10^{5}\right)$ were fixed in $4 \%$ paraformaldehyde for $45 \mathrm{~min}$ at room temperature. After rinsing with PBS, cells were permeabilized in a solution of Triton X-100 $0.1 \%$ in sodium citrate $0.1 \%$ for 2 min in ice. Samples, washed with PBS, were then incubated in the TUNEL reaction mix (Boehringer Mannheim,
Mannheim, Germany) for $1 \mathrm{~h}$ at $37^{\circ} \mathrm{C}$ in the dark, resuspended in PBS and analyzed by flow cytometry (FACScan, Becton Dickinson, Mountain View, CA, USA).

For the annexin $\mathrm{V}$ reaction, cells $\left(1 \times 10^{5}\right)$ were suspended in $195 \mu \mathrm{l}$ of binding buffer (10 mM HEPES- NaOH, pH 7.4, $140 \mathrm{mM}$ $\mathrm{NaCl}, 2.5 \mathrm{mM} \mathrm{CaCl}_{2}$ ) and $5 \mu \mathrm{l}$ of annexin (Bender System, Vienna, Austria) was added to each sample and incubated for $10 \mathrm{~min}$. After washing, cells were resuspended in binding buffer containing PI $(1 \mu \mathrm{g} /$ $\mathrm{ml}$ ) and analyzed by FACScan.

\section{Cell cycle analysis}

Adherent cells were trypsinized, fixed and stained with a PI solution as described above. The cell cycle perturbations were measured by a FACScan flow cytometer equipped with an argon laser (Becton Dickinson). At least 10000 cells were collected and evaluated for DNA content. Cell cycle distributions were calculated by LYSYS II software (Becton Dickinson).

\section{Western blot analysis}

Cell lysates were prepared according to Laemmli. ${ }^{30}$ Briefly, samples ( $80 \mu \mathrm{g} /$ /ane) were fractionated by SDS-polyacrylamide gel electrophoresis and blotted on nitrocellulose sheets. Blots were pre-blocked for $1 \mathrm{~h}$ at room temperature in PBS containing 5\% (w/v) dried non-fat milk. Filters were incubated overnight at $4{ }^{\circ} \mathrm{C}$ with antibodies to p21 WAF1 (Neomarkers, Union City, CA, USA), Bax (Pharmingen, San Diego, CA, USA), RPA (Neomarkers), p53 (Dako, Glostrup, DK, USA) or Phospho-p53 (Ser15) (New England Biolabs, Inc., Beverly, MA, USA). A rabbit anti-actin antibody (Sigma Chemical Co., St. Louis, MO, USA) was used as control for loading because actin expression is not modulated by drug exposure in our experimental conditions. Antibody binding to nitrocellulose blots was detected by chemiluminescence procedures (Amersham Pharmacia Biotech Italia, Cologno Monzese, Italy).

\section{Acknowledgments}

This work was partially supported by the Associazione Italiana per la Ricerca sul Cancro, Milan, by the Consiglio Nazionale delle Ricerche, Rome, by T Hoepli foundation and by the Ministero della Sanita', Rome, Italy.

\section{References}

1. Farrell N (1995) DNA binding and chemistry of dinuclear platinum complexes. Comm. Inorg. Chem. 16: 373-389.

2. Perego P, Caserini C, Gatti L, Carenini N, Romanelli S, Supino R, Colangelo D, Viano I, Leone R, Spinelli S, Pezzoni G, Manzotti C, Farrell Nand Zunino F (1999) A novel trinuclear platinum complex overcomes cisplatin resistance in an osteosarcoma cell system. Mol. Pharmacol. 55: 528-534.

3. Pratesi G, Perego P, Polizzi D, Righetti SC, Supino R, Caserini C, Manzotti C, Giuliani FC, Pezzoni G, Tognella S, Spinelli S, Farrell N and Zunino F (1999) A novel charged trinuclear platinum complex effective against cisplatin-resistant tumours: hypersensitivity of p53-mutant human tumour xenografts. Br. J. Cancer 80: $1912-1919$.

4. Lane DP (1992) Cancer. P53, guardian of the genome. Nature 358: 15-26.

5. Vogelstein B, Lane D and Levine AJ (2000) Surfing the p53 network. Nature 408: $307-310$.

6. Hartwell LH and Kastan MB (1994) Cell cycle control and cancer. Science 266: $1821-1828$ 
7. Gottlieb TM and Oren M (1998) p53 and apoptosis. Semin. Cancer Biol. 8: 359 368.

8. Smith GC, Cary RB, Lakin ND, Hann BC, Teo SH, Chen DJ and Jackson SP (1999) Purification and DNA binding properties of the ataxia-telangiectasia gene product ATM. Proc. Natl. Acad. Sci. USA 96: 11134-11139.

9. Gobert C, Skladanowski A and Larsen AK (1999) The interaction between p53 and DNA topoisomerase I is regulated differently in cells with wild-type and mutant p53. Proc. Natl. Acad. Sci. USA 96: 10355-10360.

10. Ashcroft M, Kubbutat MH and Vousden KH (1999) Regulation of p53function and stability by phosphorylation. Mol. Cell. Biol. 19: 1751-1758.

11. Meek DW (1998) Multisite phosphorylation and the integration of stress signals at p53. Cell Signal 10: 159-166.

12. Shieh SY, Ikeda M, Taya Y, Prives C (1997) DNA damage-induced phosphorylation of p53 alleviates inhibition by MDM2. Cell 91: 325-334.

13. Siliciano JD, Canman CE, Taya Y, SakaguchiK, Appella E and Kastan MB (1997) DNA damage induces phosphorylation of the amino terminus of $p 53$. Genes Dev. 11: $3471-3481$.

14. SakaguchiK, Herrera JE, Saito S, Miki T, Bustin M, Vassilev A, Anderson CW and Appella E (1998) DNA damage activates p53 through a phosphorylationacetylation cascade. Genes Dev. 12: 2831-2841.

15. Allan LA and Fried M (1999) p53-dependent apoptosis or growth arrest induced by different forms of radiation in U2OS cells: $\mathrm{p} 21^{\text {WAF1/CIP } 1}$ repression in UV induced apoptosis. Oncogene 18: 5403-5412.

16. Farrell N, Appleton TG, QuY, Roberts JD, Soares Fontes AP, Skov KA, Wu P and Zou $Y$ (1985) Effects of geometric isomerism and ligand substitution in bifunctional dinuclear platinum complexes on binding properties and conformational changes in DNA. Biochemistry 34: 15480-15487.

17. Dumaz N and Meek DW (1999) Serine15 phosphorylation stimulates p53 transactivation but does not directly influence interaction with HDM2. EMBO J. 18: $7002-7010$.

18. Turenne GA, Paul P, Laflair $L$ and Price BD (2001) Activation of $p 53$ transcriptional activity requires ATM's kinase domain and multiple N-terminal serine residues of $p 53$. Oncogene 20: $5100-5110$.

19. Damia G, Filiberti L, Vikhanskaya F, Carrassa L, Taya Y,D'Incalci Mand Broggini $M$ (2001) Cisplatinum and taxol induce different patterns of $p 53$ phosphorylation. Neoplasia 3: 10-16.
20. Kwon YW, Ueda S, Ueno M, Yodoi J and Masutani H (2002) Mechanism of p53dependent apoptosis induced by 3-methylcholanthrene: involvement of p53 phosphorylation and p38 MAPK. J. Biol. Chem. 277: 1837-1844.

21. Unger T, Sionov RV, Moallem E, Yee CL, Howley PM, Oren Mand Haupt Y (1999) Mutations in serines 15 and 20 of human p53 impair its apoptotic activity. Oncogene 18: 3205-3212.

22. Shono T, Tofilon PJ, Schaefer TS, Parikh D, Liu T-J and Lang FF (2002) Apoptosis induced by adenovirus-mediated p53 gene transfer in human glioma correlates with site-specific phosphorylation. Cancer Res. 62: 1069-1076.

23. Miyashita T and Reed JC (1995) Tumor suppressor p53 is a direct transcriptional activator of the human bax gene. Cell 80: 293-299.

24. El-Deiry WS, Harper JW, O'Connor PM, Velculescu VE, Canman CE, Jackman J, Pietenpol JA, Burrell M, Hill DE, Wang Y, Wiman KG, Mercer WE, Kastan MB, Kohn KW, Elledge SJ, Kinzler KW and Vogelstein B. (1994) WAF1/CIP1 is induced in p53-mediated G1 arrest and apoptosis. Cancer Res. 54:1169-1174.

25. Servidei T, Ferlini C, Riccardi A, Meco D, Scambia G, Segni G, Manzotti C and Riccardi R (2001) The novel trinuclear platinum complex BBR 3464 induces a cellular response different from cisplatin. Eur. J. Cancer 37: 930-938.

26. Patrick SM and Turchi JJ (1999). Replication protein A (RPA) binding to duplex cisplatin-damaged DNA is mediated through the generation of single-stranded DNA. J. Biol. Chem. 274: 14972-14978.

27. Turchi JJ, Henkels KM, Hermanson IL and Patrick SM (1999) Interactions of mammalian proteins with cisplatin-damaged DNA. J. Inorg. Biochem. 77: 8387.

28. Abramova NA, Russell J, Botchan M and Li R (1997) Interaction between replication protein $A$ and p53 is disrupted after UV damage in a DNA repairdependent manner. Proc. Natl. Acad. Sci. USA 94: 7186-7191.

29. Chan DW, Son S-C, Block W, Ye R, Khanna KK, Wold MS, Douglas P, Goodarzi AA, Pelley J, Taya Y, Lavin MF and Lees-Miller S (2000) Purification and characterization of ATM from human placenta. A manganese-dependent, wortmannin-sensitive serine/threonine protein kinase. J. Biol. Chem. 275 $7803-7810$.

30. Laemmli UK (1970) Cleavage of structural proteins during the assembly of the head of bacteriophage T4. Nature 227: 680-685. 